\title{
La neurociencia y el repensar neurofilosófico en la solución del problema cuerpo-mente.
}

Neuroscience and neurophilosophical rethinking in the solution of the body-mind problem.

\author{
Manuel J. Puma-Romero ${ }^{1, a}$
}

\section{RESUMEN}

La relación entre el cuerpo y la mente ha sido y es un dilema que persiste hasta hoy tras siglos de continua discusión. Tanto los filósofos como los médicos han expuesto y defendido diversas teorías sobre este tema, planteando infinidad de interrogantes y varias escuelas de pensamiento que buscan dar respuesta al problema. Esta investigación se basa en la pregunta: $\mathrm{Si}$ entendemos los orígenes de la relación entre cuerpo y mente, ¿encontraríamos las soluciones en la neurociencia y la neurofilosofía?. Se estudia la etimología de los términos, principalmente los prefijos "neuros" y "psique", para ahondar en la concepción cartesiana de la res cogitans y la res extensa. A partir de los siete pasos de la investigación filosófica, el presente ensayo propone dilucidar la esencia de este problema científico y filosófico, contrastando el dualismo y el monismo, considerando los niveles material y espiritual, y endosando el concepto de que la mente es un producto del cerebro.

PALABRAS CLAVE: Neuros, psyche, cuerpo-mente, neurociencia y neurofilosofía.

\section{SUMMARY}

The relationship between the body and the mind has been and still is a persistent dilemma that continues today after centuries of continuous discussions. Both, philosophers, and doctors have advocated diverse theories, with a myriad of questions, and various schools of thought that seek to answer the problem. This review is based on the following question: If we understand the origins of the relationship between body and mind, would the solutions be found in the fields of neuroscience and neurophilosophy? The etymology of the terms, mainly the prefixes "neuros"' and "psyche", is studied to delve into the Cartesian conception of the res cogitans and the res extensive. Based on the seven steps of philosophical research, this essay attempts to elucidate the essence of this scientific and philosophical problem contrasting dualism and monism, considering the material and spiritual levels, and embracing the concept that the mind is a product of the brain.

KEYWORDS: Neuros, psyche, body-mind, neuroscience and Neurophilosophy.

Universidad Nacional Mayor de San Marcos. Lima, Perú

a Profesor Principal; Médico Neurocirujano; Doctor en Medicina, Doctor en Filosofía; Ex Jefe del Servicio de Neurocirugía del HCFAP 


\author{
"La verdad no puede ser verdad \\ si no se ponen de acuerdo \\ tu verdad y la mía \\ y aun así, pudiera no ser verdad"
}

El presente trabajo, se encuentra basado en el pensamiento del autor descrito en el libro Las llaves de la neurociencia y de la neurofilosofia: El ser humano y la persona en la relación del cuerpo y la mente (1).

\section{PROBLEMATIZACIÓN}

El problema de la relación del cuerpo con la mente, se refiere al problema filosófico de la relación del cuerpo y el alma. El término alma deriva del griego psiche y del latín anima, pues, mente en latín es mens que se relaciona con el pensar. Este problema se ha mantenido vigente durante muchos siglos por concepciones sobre la existencia del alma como tal y no siempre como razón o conciencia que ya se encontraba presente en los socráticos, aun aceptándose actualmente que la mente es un elemento emergente del encéfalo, sin embargo, se ha ido al extremo al considerar que el problema se halla enteramente solucionado, trayendo más conflicto entre las corrientes científicas y filosóficas.

Uno de los problemas que atraviesa actualmente la sociedad en general, es la denominada "igualdad", que en la práctica se encuentra involucrada dentro de un relativismo, provocando mayor incertidumbre para aquellos que intentan buscar una solución en un enfrentamiento directo del problema, pero que muchas veces sin recurrir al consenso de expertos, especialmente porque se han dedicado a trabajar e investigar en forma particular olvidando que como profesionales, debemos ser sometidos a la evaluación científica a través de nuestras sociedades científicas y de presentar publicaciones, con la finalidad de deliberar los problemas buscando el consenso y ser comunicados científicamente, pues de lo contrario se mantendrá la incertidumbre y el relativismo. Buscar el consenso no es sólo ponerse de acuerdo con lo que pensamos, sino colocar nuestra posición como una idea más, que debe obtener la aprobación de todos 0 de la mayoría. Es así como usualmente se escucha, se escribe y se lee en múltiples artículos científicos que debemos formar equipos de trabajo. Eso es cierto, sin embargo, no pasa de ser solamente un equipo multidisciplinario e interdisciplinario, cuando lo importante es la transdisciplinariedad, donde todos nos pongamos de acuerdo en algo, buscando objetivos comunes, sino iguales.
Cuando se discute el problema de la igualdad, en muchas personas aparece las ideas de los problemas sociales que vivimos, como son la igualdad entre hombres y mujeres. Sin embargo, los seres humanos somos diferentes, aunque ambos pertenezcamos al mismo género Homo. Somos existencia humana, pero no somos iguales, pues el género taxonómicamente se divide en sexo masculino y femenino, no dice que sea masculino o femenino. Somos seres pensantes que tomamos decisiones por lo que hemos sido clasificados también como especie sapiens, diferenciándonos de otros seres de la escala animal, pues poseemos un sistema nervioso con un encéfalo privilegiado en pensar, programar y decidir, sosteniéndonos en un código de ética natural y de leyes creadas, además de podernos comunicar gracias a la genética del FOXP2 en nuestro lenguaje, pudiendo concordar y divergir ideas sobre la res cogitans y la res extensa, así como de muchas cosas que constituyen diferentes dualismos que deberán mantener la armonía de lo natural y aún en base a creencias del no ser, que solo podría conducir a un relativismo.

La creación jurídica y ética de la persona es lo que da la igualdad a los seres humanos, sin embargo, se ha buscado la forma de entenderla de múltiples maneras, tergiversando su esencia. Persona viene del vocablo griego prósopon que significa máscara, cuyas facciones representaban diferentes sentimientos y roles actorales en el antiguo teatro griego. Dichos roles y actitudes muestran la personalidad del individuo, interesando sus deberes y derechos en el concepto de igualdad entre las personas, aun sean diferentes como seres humanos. Hay seres humanos que se consideran animales como gatos, perros, etcétera y consideran que son personas también, como la persona de Dios, que en este caso sería una persona no humana. Los ángeles, los alienígenas y los animales son personas no humanas y todos tienen derechos y obligaciones, aunque estos últimos muchas veces no se cumplen. En la situación de igualdad de derechos, se ha elaborado leyes que lo sustenten la igualdad ya que no solo somos seres biológicos, sino sociales también, aplicándose la figura de la persona. Sin embargo, se puede decir al revés, que somos seres biológicos y no solo seres sociales, lo que nos haría ver como seres humanos y entonces somos diferentes, y nadie puede cambiar las leyes naturales, aun sean modificadas en forma complaciente las leyes humanas, lo que podrían hacer más complejo el problema de la relación del cuerpo y la mente, creando estados desarmónicos, como los que se encuentran en los trastornos del comportamiento, que son negados como enfermedades, pero que sin 
La neurociencia y el repensar neurofilosófico en la solución del problema cuerpo-mente.

embargo, se encuentra en los procesos de índole patológica.

El evidente distanciamiento entre los profesionales de la salud solo ha llevado a acrecentar el iterativo discurso sobre lo cognitivo, lo conativo y la personalidad, como si fuera el problema principal de la relación cuerpo y mente, provocando un ensimismamiento, debido que aquellos que han seguido esta única idea, han creído ver en el árbol un todo, sin mirar lo vasto del bosque que es el sistema nervioso. Los procesos mórbidos que afectan a muchos enfermos denominados mentales y orgánicos tienen la misma significancia en la importancia de ser tratados y la neurociencia no puede quedar acotada en solo los problemas de la mente o del alma, pues precisamente fueron los médicos que bajo el método de la clínica y el correlato fisiopatológico, trataron clínica y quirúrgicamente a paralíticos, sordos y ciegos, confirmando áreas topográficas cerebrales, que ha ayudado a la investigación de la neurociencia. Parte de este problema es que todo lo que se desconoce o produce duda, se lo ha atribuido a lo psíquico y peor aun viéndolo como etéreo o inexistente. Si se desconoce lo que es el sistema nervioso y podemos decir, que sin sistema nervioso no hay mente. Es pues, en esa res extensa donde se producen múltiples problemas, no solo traumáticos, metabólicos, infecciosos y otros que producen en los enfermos una serie de disfunciones; acompañadas muchas veces de dolor, que al no poder concluir en un correlato clínico, muchos pacientes tienen que cargan con sus dolencias, pues se ha considerado que su problema psíquico corresponde a la esfera de lo espiritual. Esto nos obliga a repensar sobre nuestros perfiles académicos y a sabernos limitar en el ejercicio profesional, demostrando nuestras competencias y evitando el intrusismo y la intromisión.

Si tomamos en cuenta que la enseñanza de pregrado es diferente en cada profesión, muchas asignaturas pueden llevar el mismo nombre, pero no son las mismas, por las competencias, los objetivos. Entonces, ¿cómo se puede mezclar a profesionales de diferente profesión a estudiar una maestría o un doctorado sobre neurociencia, intentando unificarlos cuando sus competencias son de perfil diferente? De tal manera que, algunos profesionales se van a sentir limitados al no poder sustentar lo que nunca tuvieron como base académica y científica, sin embargo, culminan con el mismo grado académico, repitiendo la teorización, pero sin obtener el privilegio clínico, el lenguaje bioquímico y genético aplicado al correlato clínico. Además que, las maestrías y los doctorados son estudios donde se desarrolla el pensamiento crítico y ético en los alumnos, o sea, un punto de vista más objetivo de las cosas; pero no es una vía académica de especialización, como algunos profesionales creen o lo han considerado. Para ser un profesional especializado se tiene que estudiar un programa de post grado de 3 a 5 años.

\section{ANÁLISIS}

Actualmente sabemos que en la relación de la res extensa con la res cogitans, la sustancia segunda es emergente de la primera, pero para llegar a esta concepción de uso diario en medicina han pasado aproximadamente 26 siglos de estudio e investigación desde los sabios de Grecia, pasando por los filósofos naturalistas y socráticos hasta la actualidad; quedando la tercera sustancia cartesiana o sustancia infinita, fuera de contexto científico para unos, mientras que para otros, han considerado su importancia y necesidad de un mundo espiritual, como la existencia de Dios, sea parte del confort en el manejo terapéutico como parte de las creencias que deben respetarse; evitándose confundir el alma o la psique con lo espiritual.

En la evolución del pensamiento humano, aparece el daimon socrático, con poderes sobrenaturales, que hablaba al interior de la persona induciéndolo, sin embargo, la razón no recibió órdenes, permitiéndole que su autonomía buscara la verdad. Aquel daimon de los diálogos de Platón, le habla a Sócrates en el Banquete, diciéndole lo que no tiene que hacer, tomando una connotación negativa posteriormente, como demonio en la corriente del cristianismo, en que se hace presente también los ángeles con igual misión, pero como mensajeros buenos. Hoy día es inaceptable la interpretación de seres positivos o negativos que nos hablan hacia nuestro interior, haciendo una explicación diferente, como la existencia de la consciencia y de la conciencia, que es o puede ser tergiversado por personas con mucho ahínco religioso, pero que puede estar presente como alucinaciones auditivas, formando parte de un cuadro psicótico, cuya explicación sería la estimulación de áreas cerebrales 41, 42 o la de Heschl, que entre otras respuestas al ser estimulado produce susurros. Sin embargo, al no ser conocida su explicación fisiopatológica, así como de no interpretar adecuadamente la cultura y las creencias del enfermo, puede ser mal explicado e inclusive llevar a un error terapéutico, por quienes no manejan los campos definidos de la neurología y la psiquiatría, pues podría estar escondiendo el cuadro de un proceso expansivo 
o isquémico.

El problema del cuerpo y la mente es muy amplio, no solo abarca el ángulo neurológico en sí, pero es su punto de partida, en el que se entremezcla lo social, lo sociológico y lo antropológico. Así mismo, el uso indistinto de neurociencia y neurociencias, como la aplicación del prefijo "neuros" como un logo en cursos y cursillos, que muchas veces son enteramente de índole de la psicología, y podrían ubicarse mejor en la psicobiología y que además no necesariamente tienen por finalidad el correlato clínico y el conocimiento de lo biológico con lo neurológico, que busque explicar porque es neuroeconomía, neuroingeniería, neuropolítica, neurolingüística, neuroaudición, etcétera, lo que nos lleva a un repensar epistemológico sobre el neurotodo y la neuronada, es decir que, desde este punto de vista, el todo relacionado al prefijo neuro o neurotodo no se puede alcanzar siempre y la neuronada se alcanza fácilmente. Esto es lo que viene sucediendo cuando se aplica mal el prefijo neuros. Los cursos en mención muchas veces son dictados por llamados neurocientíficos, sin embargo, existen criterios para serlo, como veremos más adelante. También, estos cursos y cursillos son dictados por llamados entrenadores, guías, etcétera, que son profesionales de diferentes competencias a las médicas y con muy poco o nada de entrenamiento y conocimiento de las áreas neurológicas. Cuando me refiero al todo y la nada, relacionada al prefijo neuros, lo que estoy haciendo es hacer referencia al contenido de conocimiento que se encuentra al usar el prefijo neuros, que puede ser mucho o nada, teniendo en cuenta que en la antigüedad griega, la nada fue estudiada como un problema filosófico, que algunos filósofos la interpretaron como espacio, sin embargo, ese espacio no puede separarse de lo material, pero que, en la mente humana sí podría existir el vacío de conocimiento o podría dicho conocimiento componer el todo. La neurología clínica y quirúrgica no comienza con un curso de neurología o de neurocirugía que se estudian en los últimos años de la carrera de medicina humana; comienza con todas las neurociencias que las denomino básicas como la neuroanatomía, neurofisiología, neurobioquímica, neurofarmacología, neurosemiología, etcétera, que deben ser relacionados con el conocimiento de los diferentes sistemas, aparatos y órganos del cuerpo humano, de otra manera cómo pretenderíamos saber neurología, sin correlacionarlas con el compromiso de otros órganos, lo que conduce a la dedicación del ejercicio profesional en el campo de la neurociencia durante toda la vida.

Se ha especulado también con respecto a los avances tecnológicos, produciéndose muchas veces mitos en la neurociencias, especialmente por no médicos, con la llamada neuro tecnología, haciendo "real" en humanos, lo que se está estudiando recién en animales como la colocación de chips, neuromoduladores, diferentes tipos de implantes en el cerebro a través de robots que aún se hallan en investigación, pero que en sus razones, ya los hacen ver, caminar y transformar la conducta, el comportamiento y hasta la inteligencia humana, confundiendo con un lenguaje connotado sobre redes neuronales. Como neurocirujano con más de 40 años de experiencia, la verdad es que vamos avanzando sobre el manejo de la enfermedad de Parkinson a través de neuro estimuladores o marcapasos que se usan también en la epilepsia, la distonía, la depresión, pero muchos pacientes necesitan aun de la bioquímica como tratamiento. Cuando se coloca marcapasos en pacientes postraumáticos con alteración grave de la conciencia, hay que tener presente que existen mecanismos neurofisiológicos y neurobioquímicos, como metabólicos, que recuperan las llamadas células en penumbra y que no son milagros religiosos, ni necesariamente la colocación de un implante cerebral, sino los éxitos de la ciencia en la atención oportuna del manejo clínico y quirúrgico de la hipertensión endocraneana, así como el cuidado en las unidades de intensivismo, pero también hay que reconocer la propia naturaleza del enfermo.

\section{DEFINIENDO EL PROBLEMA}

De acuerdo a la concesión aristotélica, para saber algo hay que empezar por el principio, por el arkhé. Cuando estamos frente a un problema podemos analizarlo desde un sentido ordinario o desde un sentido estricto y observamos si tiene historicidad científica, filosófica o ambos, y el problema que investigamos los tiene desde hace 26 siglos, por lo tanto es un problema vigente que se presenta como fuente del conocimiento de la neurociencia, conduciéndola a la búsqueda de solución o soluciones, poniendo en marcha todos los conocimientos posibles. Este problema fue enfrentado por estudiosos de las corrientes filosóficas primero, pues inicialmente la filosofía y la ciencia eran uno solo, coincidiendo en "un conocer las causas" (2), y fue recién a mediados de la edad media cuando adquieren características diferenciales en forma progresiva separándose la filosofía de la ciencia, destacando el método experimental de Roger Bacon quien introduce un nuevo método en la ciencia y como dice Vicente Llamas (3) sobre Bacon, extraído de Op. maius VI, c.1. "Sin experiencia nada puede ser suficientemente conocido" $(3, \mathrm{p} 310)$, pues consideraba que solo había 
dos caminos para llegar al conocimiento, la experiencia y el razonamiento.

Los problemas tienen sentidos diversos como, ser médicos, sociales, antropológicos, matemáticos, etcétera y no se puede tratar de penetrar en todos, porque son forma diferente y si el problema estuviese bajo una proposición apofántica, no encontraríamos la solución en una respuesta lacónica, cuando la respuesta está en la demostración de la fisiología emergente del sistema nervioso. La solución de un problema se encuentra muchas veces en el interés por el mismo tema y aunque se ha concretado que la mente es producto del encéfalo, allí recién comienza el problema de que en su solución concuerde la realidad con la razón y pueda ser demostrada de acuerdo a los avances tecnológicos, aunque la argumentación presente este imbuida en el relativismo, la opinión y la qualia.

En nuestra definición del problema, Si entendemos los orígenes de la relación entre cuerpo y mente, ¿encontraríamos las soluciones en la neurociencia y la neurofilosofía?

\section{HIPÓTESIS}

Con la neurociencia y el repensar neurofilosófico se dará solución a los problemas de la relación del cuerpo y la mente.

\section{ARGUMENTO}

\section{Sabios y Filósofos}

Fue gracias a Tales de Mileto, que cambió las creencias, el mito, la fábula por el logos o la razón. Fue considerado por Aristóteles, como el primero de los sabios de la physis, que vivió entre los "años 624 - 547 a. C., y consideró que el principio de todas las cosas se hallaba en el agua" (4). Tales, no acuñó el término filosofía, sino Pitágoras de Samos que vivió entre los "años 580-500 a. C." (5), sustentado en Diógenes Laercio que narra "En cuanto al nombre, Pitágoras fue el primero que se lo impuso llamándose filósofo, estando en conversación familiar en Sición con Leontes, tirano de los sicioneses o fliaseos, como refiere Heráclides Póntico en el libro que escribió De la intercepción de la respiración, Ninguno de los hombres -dijo Pitágoras- es sabio; lo es solo Dios" (6). Ser un filósofo no es ser sabio, es ser amante de sophya, de allí que el investigador de la neurociencia en busca del conocimiento neurológico se convierte en un amante y conforme va aumentando su amor, propugna la neurofilosofía, permitiéndonos desacotar a la neurociencia, como lo haría la filosofía con su hija la ciencia, es decir preguntarle, creando el problema que es la fuente del conocimiento y el conocimiento en sí también origina la felicidad. Pedro Laín Entralgo se refiere al aristotelismo como la filosofía más abierta a la ciencia, dice que la felicidad se lograba con el afán de saber. También estuvo presente la tékhne, pero Aristóteles coloca a la episteme por encima, sin embargo, le permitió al hombre dominar fuerzas extrañas y como dice en un verso el poeta Antifón, que explica por qué con los griegos comienza la edad técnica: "Con el arte (tékhne) vencemos donde Natura nos vence" (7). Es esa tékhne lo que nos permite a los médicos modificar el medio y adoptarlo a nuestras necesidades para dar respuestas en beneficio del enfermo.

El agua de Tales, el aire de Anaxímenes de Mileto, el fuego de Heraclito de Efeso y la tierra de Jenófanes de Colofón, fueron los principios que más tarde consagró la teoría de los humores relacionando los cuatro elementos con el cuerpo y sus órganos, como el agua con la flema y el cerebro. La tierra con la bilis negra y el bazo; el fuego con la bilis amarilla y el hígado y el aire con la sangre y el corazón. El ser humano no solo es un ser físico, sino que posee funciones atribuidas al alma, al espíritu, a la mente, la conciencia, cambiando lo etéreo por lo psíquico con bases biológicas, así como el movimiento con áreas motoras cerebrales y la sensibilidad, y las sensaciones con áreas topográficas cerebrales también, conduciéndonos a repensar que aquello ya no se relacionaba con el primer motor, con Dios, sino con los genes, con los neurotransmisores como el origen de la expresión del alma. El pensamiento griego germinó nuevas concepciones como el logos de Heraclito de Efeso que pensó que el principio se hallaba en la razón, en el discurso, mientras que Anaxágoras de Clazomene pensó en el nous, la mente, la inteligencia. El problema del cuerpo y la mente estaba planteado entre los filósofos y los médicos griegos que al tratar dolencias humanas los clasificaron en humores, como los sanguíneos en los artesanos, los coléricos representados en los guardianes o aquellos idealistas considerados de comportamiento melancólico y los racionales como los flemáticos. Por lo que para mantener la salud fue necesario mantener el equilibrio, mantener el cosmos, sin embargo, el caos constituía el movimiento, la fisiología y en ese proceso, la physis o naturaleza del hombre que nos hace ser diferentes, como parte de la constitución humana, como dice en sus sentencias el 
filósofo Biante: "Ser fuerte en el cuerpo es obra de la Naturaleza" (6), pensamiento que se observa reflejado en la experiencia de los antiguos médicos que, cuando la ciencia no puede aportar más, entonces, frente a la gravedad del enfermo, consideraban que había que darle tiempo a la naturaleza y como usualmente escuchamos y decimos tiempo al tiempo, refiriéndose a la respuesta fisiológica del organismo, al movimiento restaurador de la materia, diferenciándola de la obra del hombre que ya actuó sobre la causa probable, pero que en la naturaleza queda su respuesta en la causa final.

\section{Psyche o alma}

Los antiguos griegos consideraron que el alma percibía unas cosas por medio del cuerpo a través de la visión y la audición y otras por sí misma. Las primeras eran cosas sensibles y las otras intelectuales. En el pensamiento aristotélico, la función era emergente de los órganos, como podría ser el sonido de una flauta, pero, su existencia no dependía del sonido, a menos que fuera necesario saber sobre su función o su existencia, pues al estar lejana e inmóvil no sabríamos de ella. Al soplar la flauta, emitirá un ruido, un sonido o una melodía. Por un lado, se dirá que es la ejecución de un individuo entrenado al tocar una melodía o lo contrario si solo emite ruidos. Alguien dirá que es un ser virtuoso que toca con el alma, pero qué lo hace tocar así. Es probable, que se explique que es debido a una serie de reacciones bioquímicas y electroquímicas del cuerpo. Pero quien las hace funcionar o de quien dependen de que se produzca tales funciones. Alguien dirá que es producto de la naturaleza, de una causa creadora o el poder de Dios, que es el creador del movimiento que se encuentra en todas partes, en el cosmos, en el universo, esperando que "Dios decida". Alguien considerará que existe un ser, un alma, que como pasajero dentro de nosotros, se encuentra unida al primer motor, guiado por el espíritu. Pero, existían otras concepciones como la de Anaximandro de Mileto, como dice Abbagnano (8), que su arkhé se encontraba en el Ápeiron, considerando que los elementos de la materia son indefinidos e ilimitados, es decir que, más que una materia compuesta de varios elementos era una composición de cualidades. La idea, de lo infinito, que en todas las cosas podía constar de una sustancia no observable, era eterna y no se podía destruir. Esta concepción nos lleva a pensar en la energía. Pasaron muchos siglos y después de muchos experimentos realizados, fueron sentadas la bases por Thompson, Davy, Mayer entre los siglos XVII y XVIII y como dice Pons Musso (9), se estableció el principio de la conservación de la energía por Helmholtz y Joule; siendo el último quien realizó una serie de experimentos, no encontrando un hecho de poder crear o destruir la energía conduciéndolo a aceptar en forma universal este principio como el resultado de su experiencia. El primer principio de la termodinámica es una generalización de la conservación de la energía que dice: "La energía no se crea ni se destruye, solo se transforma en el curso de los fenómenos". El alma considerada como energía, no se crea, ni se destruye, en Sócrates, se transmigra. En el Fedón o del Alma (10), podemos analizar su pensamiento con respecto a la muerte, pues al dirigirse a Simmias le dice que el alma es un ser más durable ya que el cuerpo es un ser débil y dura menos, mientras que el alma renueva el vestido perecible durante la vida, pero cuando llega el momento de la muerte viste su último traje y este será al que sobreviva al alma, pero al morir el alma, el cuerpo se corrompe. En algunos existen después de la muerte y renacen muchas veces para morir de nuevo, de tal manera que un alma fuerte puede usar muchos cuerpos. Lo que explica Sócrates es sobre la reencarnación por un lado y que el cuerpo al ir cambiando mantiene el alma también, hasta que llegará un momento que perezca el alma. Sócrates explica también, que el alma existe antes de nacer, pero el conocimiento se pierde en el nacimiento, pudiendo recobrarlo con los sentidos del cuerpo, constituyendo la teoría de la reminiscencia. La idea de que el alma al pasar de un cuerpo a otro a manera de reencarnación también se encuentra en el pensamiento de los órficos y los pitagóricos, como metempsicosis que significa por una parte "en medio, entremedias, juntamente, además; en seguida, a continuación, después" (11) y en la composición del término es "soplo, hálito, aliento vital; fuerza vital, alma (11), viene a ser el paso de las almas de un cuerpo a otro en forma sucesiva hasta la liberación definitiva. Esta concepción nos conduce a la explicación del budista Dr. Walpola Rahula, sobre el renacimiento en Mankind's Search for God, que dice: "Un ser es simplemente una combinación de fuerzas o energías físicas y mentales. Lo que llamamos muerte es el cese total de las funciones del cuerpo físico. ¿Cesan por completo todas estas fuerzas y energías cuando el cuerpo deja de funcionar? [...]" (12), lo que nos lleva a interpretar la similitud de pensamiento de la corriente budista y órfica en la concepción de que el alma como energía se transmigra.

Platón y Aristóteles, consideraron la dualidad, en Platón, el alma era más pura ya que correspondía al mundo de las ideas; mientras que el soma podía sufrir cambios, pues pertenecía al mundo sensible. En 
La neurociencia y el repensar neurofilosófico en la solución del problema cuerpo-mente.

Aristóteles, la dualidad se encontraba en la materia y en la forma, en la potencia y en el acto, en el cuerpo y en el alma, con un pensamiento fisiológico tal vez por la influencia de Nicómaco, su padre, que fue un Asclepiadea. El arkhé de las funciones vitales residía en el alma que eran causa y principio del cuerpo; por lo tanto, si se alteraba el alma, el cuerpo se afectaba. Platón, pensó que el alma era inmortal y en Aristóteles al perecer el cuerpo, el alma perecía también. Diógenes Laercio, sobre Platón, dice que el alma se divide en tres partes, "El alma racional (cabeza) es la causa y origen del consejo, del pensar, del consultar y demás semejantes (6). La parte concupiscible (abdomen) es la causa de apetecer la comida, el coito y semejantes. Y la parte irascible (corazón) es la causa del ánimo, del deleite, del dolor y de la ira." (6). El hilemorfismo de Aristóteles en su teoría sobre la materia y la forma, en su concepción sobre el alma sería la función, como por ejemplo en un martillo sería el golpe y en un cuchillo, el corte. Si un cuchillo no tiene filo o no corta, no tendría función, por lo que se consideraría que no tendría alma. Entonces, ¿un ciego, tiene alma? Si tiene alma, aunque una parte de su cuerpo no la tendría. Igual sucedería con un manco o un cojo, entonces sería una parte del alma que no tendría función. El problema del alma no es un caso cerrado, históricamente precedió al desarrollo de la psicología y sigue siendo la base de lo moral, lo religioso, y lo metafísico.

\section{Una nueva filosofía}

El pensamiento platónico y aristotélico continuó a través del tiempo hasta la actualidad, influenciando el pensamiento de muchos estudiosos, como algunos dogmas cristianos que aseveran la existencia de un dios que ha creado todo lo que nosotros conocemos y de lo que podríamos pensar; así como de un alma creada de la nada, que tenía por finalidad mantener una conexión entre el ser humano y lo divino. En el medioevo, los filósofos consideraban que el alma funcionaba como memoria y permitía el entendimiento y voluntad de carácter personal, por lo que Descartes quiso sentar las bases de un pensamiento racional autónomo de las ideas religiosas; capaz, por sí solo, de descubrir lo que era cierto. Tales concepciones llevaron a un cambio radical sobre los planteamientos argumentados por Platón y Aristóteles, relacionados al Cosmos teleológico, que parecen obedecer un objetivo o una finalidad de un ser inteligente; mientras que en el nuevo planteamiento cartesiano fue llamado Cosmos mecanicista, Descartes quiso hacer conocer, en forma matemática, las leyes que producían los fenómenos naturales; por lo cual, desterraba la idea en la relación entre el alma y el cuerpo para dar paso a la relación entre el cuerpo y la mente que, como producto emergente, el pensar y el repensar, explicaba su existencia. En su obra, Le Traite de L'homme, contribuye con un pensamiento neurológico y fisiológico al proponer la teoría de la respuesta; utilizando, para su explicación, conceptos de su época, relacionados a la mecánica y la óptica; de tal manera que, a través de una conducción por vía nerviosa recorrida por los espíritus animales, que viajaban desde la periferia hasta el cerebro, de tal manera que si un pie era estimulado por el fuego, se produciría un mecanismo que abriría un poro o conducto en el que se insertaría una cuerda que, al tirar de ella, haría sonar una campana, como símbolo de recorrido de la estimulación; por lo que, el calor viajaría por un tubo hasta la glándula pineal, que Descartes consideraba como el Centro Sensorium; de tal manera que, al llegar el estímulo térmico, desencadenaría una respuesta de retirada en forma inconsciente para evitar la quemadura o de continuar la lesión. Estas respuestas que se producían en el cuerpo, como el comportamiento, el pensamiento, las pasiones o emociones y la propia acción eran productos del impulso de pequeños espíritus animales o espíritus vitales; era el vínculo entre el alma y el cuerpo. Son estos espíritus que siente el alma para poder actuar, pero ¿de dónde provienen estos espíritus vitales? Esa fue la preocupación de la ciencia en demostrar la inexistencia de los espíritus vitales que, a través de la neurofisiología, se explicó como impulsos nerviosos y la neuro conducción, gracias a los estudios de neurólogos clínicos y quirúrgicos.

\section{Los médicos}

El pensamiento absoluto que ha persistido a través del tiempo, y que solo buscó el beneficio personal, conduciendo a que muchos otros pensadores científicos y filósofos fueran perseguidos, desterrados, maltratados y obligados a cambiar los hallazgos de sus estudios para evitar la prisión o la muerte, como sucedió con Galileo Galilei, Giordano Bruno, Johannes Kepler, Descartes y otros científicos. En relación al concepto de salud, Avicenna e Hipócrates ya lo tenían, pues relacionaban el estado de equilibrio del cuerpo humano con los humores, y estos con los estados emocionales, que al encontrarse alterados era un estado de desequilibrio o de desarmonía del cuerpo que muchos siglos después interpretaríamos como las alteraciones bioquímicas que se expresan a través de diferentes manifestaciones clínicas con correlato fisiopatológico. Diógenes Laercio (6) narra que Alcmeón de Crotona, discípulo de Pitágoras, 
trataba de cosas de la medicina y contradictoriamente con la fisiología, pues decía Aristóteles, sobre las cosas opuestas entre sí, como lo amargo y lo dulce, lo caliente y lo frío, etcétera y Favorino en su Historia varia, dice que fue el primero en escribir sobre el orden de la naturaleza. Ramón Alonso (13), en su libro Historia del cerebro, dice que Alcmeón fue el primer filósofo que dictaminó que la funciones psíquicas se encontraban en el cerebro, sustentándose en las observaciones de enfermos, así como diferentes experimentos que le hizo afirmar que los órganos de los sentidos se encontraban conectados al cerebro por nervios o poros como lo mencionó posteriormente Descartes. Para Alcmeón la conciencia, la vida psíquica, incluyendo la epilepsia eran dependientes del cerebro, lo que nos hace recordar a Hipócrates que descarta lo divino en las enfermedades, como dice García Gual, sobre el pensamiento hipocrático en relación a la Enfermedad Sagrada: "De acuerdo con esto considero que el cerebro tiene el mayor poder en el hombre. Pues nuestro intérprete, cuando está sano, de los estímulos que le provienen del aire. El aire le proporciona el entendimiento. Los ojos, los oídos, la lengua, las manos y los pies ejecutan aquello que el cerebro apercibe. Pues en todo el cuerpo hay entendimiento, en tanto que hay participación del aire, pero el cerebro es el transmisor de la conciencia" (14). El manejo de la medicina, como la cirugía, a través de la historia, ha sufrido detracciones especialmente por pensadores no médicos, imponiendo sus ideas oponiéndose al kheirurgós, término griego que, como dice Fernández, está compuesto por 'kheír' o mano y 'érgon', obra o trabajo (15). El trabajo quirúrgico, fue relegado por los antiguos filósofos, pues ellos consideraban que el cuerpo estaba guiado por una mente externa, o como un ente iluminado, de allí el interés por realizar pases mágicos sin bases científicas y rezos basados en la fe, intentando curar. Actualmente, se estudia si los rezos o el acto de orar en sí, basados en la fe, tienen repercusiones neuro imagenológicas correlacionándolos con la bioquímica cerebral.

Los conocimientos de Alcmeón y de Hipócrates, sirvieron posteriormente a médicos y cirujanos y es muy probable que también lo haya recibido Aristóteles. El médico cirujano Herófilo de Calcedonia vivió a mediados del siglo IV a. C. (16), consideró que la razón se encontraba en el cerebro y era este órgano el que dirigía al cuerpo. Es probable que este pensamiento estuviera sustentado en el conocimiento obtenido a través de las disecciones públicas practicadas en reos. Es conocido por su Prensa venosa en la fosa posterior del cráneo, que lleva su nombre. Es importante recordar, también, las prestigiosas escuelas médicas como la de Alejandría del siglo III a.C., por sus grandes aportes de términos que enriquecieron la Nómina Anatómica, como el parénkhyma y la triplokya del famoso médico cirujano y neuro anatomista Erasistrató de Ceos del siglo III a. C. (17), que distinguió los hemisferios del cerebelo, relacionados a la coordinación motriz. Se le ha considerado un precursor del método comparativo al estudiar el plegamiento de las circunvoluciones en humanos y animales. Gracias a los estudios de Erasistrato, que trató de resolver a través de un fisiologismo incipiente pero innovador, relacionando la triplokya, el VAN como un sistema que actuaba a un nivel sub sensible en el organismo, conduciendo el pneuma vital a través de las arterias, mientras que las venas conducían la sangre nutriendo y permitiendo la alimentación del cuerpo y los nervios conducía las sensaciones y el movimiento. Utilizó el término parénquima o "sustancia de los órganos" (18), que se interpreta como un destilado que se encuentra al lado de lo que lo produce, de tal manera que es probable que los antiguos médicos al observar el encéfalo, veían a este órgano muy vascularizado como una madeja de vasos sanguíneos, rodeado de un tejido parenquimatoso que era el resultado de un destilado de la sangre de los vasos como cuando se coagula formando una masa a diferencia que cuando se encontraba in situ era un órgano vital o funcional. Estos conocimientos le sirvieron posteriormente a Claudius Galeno de Pérgamo que vivió entre los años 130 - c. 216 (17) intentar precisar la relación entre la vida espiritual y el cerebro. Galeno planteó el problema de la localización directa de los fenómenos psíquicos con las estructuras cerebrales, contribuyendo al conocimiento del sistema nervioso central.

Los cuatro elementos y el nous, buscados en la naturaleza del ser, fueron explicados a través de los cambios metabólicos y en los circuitos neuronales que dan asiento a la conciencia. La aceptación y materialización de estas bases neurológicas se fueron produciendo desde los cambios químicos y metabólicos en las celdillas de los microscopistas del siglo XVII. Robert Hooke, definió la célula como la unidad fundamental de toda forma de vida, pero no el elemento explicativo teleológico. Aunque el principio vital se mantuvo, fueron apareciendo nuevas teorías que los filósofos trataban de explicar y los científicos buscaban. Como dice Abbagnano (8), apareció la teoría fibrilar del médico francés Jean Fernel y la alquimia del famoso Paracelso, reevaluada por la iatroquímica del médico Jan Baptista van Helmont, conocimientos importantes en el siglo XVI - XVII, 
que permitieron al médico y químico alemán Georg Ernst Stahl en el siglo XVIII, afirmar que el principio vital podría explicar la vida a través de la materia como aquella potencia aristotélica, la existencia de un ánima, en la generación espontánea, a partir de la materia orgánica, teoría apoyada por Descartes, Bacon y Newton, rechazada desde el siglo XVII, por el médico, naturalista Francesco Redi, demostrando su falsedad.

\section{CRÍTICA}

La neurociencia pudo dar soluciones no solo a través del argumento, sino con la demostración relacionados al trabajo de los médicos, que fueron dando nuevas ideas, produciéndose cambios en las concepciones, platónicas y aristotélicas, formulado en una nueva filosofía cartesiana. Los filósofos y científicos con su fundamento racional, especialmente en los primeros, y empírico, en los segundos, buscaban entender la relación entre el cuerpo y la mente, surgiendo también, corrientes científicas y filosóficas que defendieron posiciones dualistas, monistas materialistas y monistas espiritualistas.

Rechazado el mito, la metáfora pasó a ser mejor entendida, uniendo la filosofía a la religión, manteniendo la idea de un alma inmaterial, una materia fina unida al cuerpo, lo que en un principio fue en Aristóteles la psyche o la psicología o del alma. Actualmente, si se tratara de sostener que la formación del universo fue a partir del caos y del cosmos, se buscaría inmediatamente una respuesta que sostuviera ese dualismo, pero, si alguien tratara de decir que fue debido a una lucha entre los dioses del Olimpo, sería inmediatamente refutado por los conocimientos científicos actuales como que el Big Bang "se produjo hace 13,800 millones de años" (19). Aunque esto es una aproximación matemática a la creación de materia, espacio y tiempo. Pero, surgirían otras preguntas como, ¿qué hubo antes del Big Bang? Frente a esta situación se harían presente los defensores de un monismo, que el universo está constituido por una única sustancia que es el arkhé. De igual manera se han encontrado enfrentados los defensores del dualismo cartesiano, frente a un monismo materialista que sostiene que el ser humano es materia y no existe la inmortalidad del alma y sobre esta postura se trata de imponer una posición opuesta o un monismo espiritualista ya que todo lo que existe considerado real es producto de nuestra mente, pues no existe materia.

El hecho de que la ciencia se separaba de la filosofía no fue sino para entrar en una serie de contraposiciones, por ejemplo Vesalio, en el siglo XVI, estudió detalladamente los ventrículos cerebrales como lo hizo Samuel Thomas Von Sömmerring en 1796; sin embargo, continuó la idea, de que el sustrato de los procesos psíquicos eran los spiriti animales que fluían por los nervios. Este término espíritu, como dice Ferrater Mora (20), se ha usado con frecuencia para traducir los vocablos griegos nous y pneuma, surgiendo controversias. El psyche o alma es un principio vivificante, afectivo, emotivo mientras que el nous es un principio pensante e intelectual. Por lo tanto, es el psyche que estaría relacionado con los términos espíritus animales o espíritus vitales, que se utilizó en diversas épocas para referirse a alguna realidad orgánica o psico-orgánica, que anteriormente nos hemos referido con respecto a las funciones vitales. De acuerdo con Descartes nuestras necesidades y nuestras pasiones no serían sino mecanismos expresados de los espíritus animales y se conducirían a través de los nervios, teniendo como mediador la glándula pineal, considerada el centro del alma. Fue necesario la importancia de la demostración práctica sobre el racionalismo cartesiano, eliminando los prejuicios con un pensamiento baconiano, que trataba de erradicar los ídolos de la mente humana; sin embargo, se complicó más el problema del cuerpo y la mente, pues se formaron diferentes corrientes de pensamiento con bases espiritualistas. Por un lado, el ocasionalismo de Malebranche continuado por un monismo de Baruch Spinoza en siglo XVII y los seguidores de la diversidad cualitativa de los seres por la existencia de las mónadas de Leibniz, que sostuvo que los seres humanos poseían alma como sujetos independientes pero que se mantenían en armonía preestablecida por Dios, introdujeron el término apercepción como una percepción atenta, acompañada de conciencia. Sus concepciones sirvieron para dar sustento a la psicología cognitiva y la psicología experimental de Wundt. Frente a las diferentes corrientes del pensamiento que se hallaban en forma dispersa, pues cada uno buscaba su verdad, Kant busco la unidad, comparando la filosofía de Leibniz con la del filósofo y economista David Hume, pues con el pensamiento de la razón y la experiencia debían coincidir en sus apreciaciones, demostrando que solo la razón era incapaz de descubrir la verdad. La razón, por un lado, y el dogma por otro hicieron ver la mente como alma y no como producto emergente del encéfalo.

\section{RECTIFICANDO}


En nuestra investigación, hemos observado los términos psyche y neuro; con un significado relacionado al alma, a la psicología, pero también como inteligencia y razón y también al sistema nervioso. Cada una de estas concepciones, defendidas por corrientes empiristas y racionalistas, pero también mediadas por un pensamiento kantiano. Los trabajos de los médicos dieron a luz a través de la mayéutica socrática, la existencia de la psyche como alma, pero también como psicología, con visiones diferentes en el tiempo, para que finalmente, no tuviera relación con un primer motor inmóvil aristotélico. Los estudiosos e investigadores, a lo largo de la historia de la neurociencia, fueron médicos, especialmente, neurólogos clínicos y quirúrgicos, dedicados a diferentes disciplinas, como neuroanatomistas, neuropatólogos, neurofisiólogos, neurobioquímicos, etcétera; pero que en el rol de investigadores de la mente fueron llamados "psicólogos" que buscaban relacionar al sistema nervioso con funciones aún desconocidas en ese momento y que actualmente se continúan estudiando, buscando demostrar la función en un correlato biológico, pero no de investigación exclusiva de la neurociencia.

En nuestra búsqueda de los orígenes del problema del cuerpo y la mente con los orígenes de la neurociencia, se entremezcla el término psicólogo con la psicología actual y correlaciona a sus representantes de dichas corrientes con la psicología antigua. Sin embargo, fue gracias a la creación del primer laboratorio científico de psicología en 1879, por el médico, fisiólogo y filósofo alemán Wilhem Maximilian Wund, inició la Psicología Científica. Logrando el profesor de fisiología de medicina humana de la Universidad alemana de Leipzig, que la psicología no fuera considerada más una rama de la filosofía, como se puede encontrar en su recordada obra "Fundamentos de la Psicología Fisiológica", donde muestra lo objetivo y lo subjetivo del comportamiento humano. Wund, consideraba que la psicología es la ciencia de la experiencia y que ésta no debía recurrir a la metafísica. Así mismo pensaba que no era posible distinguir entre la experiencia interna y la externa, puesto que ambas se producían de igual manera. Este investigador del campo fisiológico pensaba que cuando la experiencia ante algún estímulo se medía con la ayuda de instrumentos, quedaba incluida en el campo de la física, por lo tanto los físicos tienen sus instrumentos y en los psicólogos su herramienta es la autoobservación experimental o la introspección, donde predominan dos elementos básicos en la vida mental: las sensaciones y los sentimientos. Este famoso médico adopto un modelo de la mente con énfasis en los principios químicos, dejando de lado el mecanicismo, ya que la mente es una fuerza creativa, dinámica, volitiva y no puede ser entendida por la simple identificación de sus elementos o su estructura estática, debiéndose entender a través del análisis de su actividad. Aún con los avances de Wund y de su psicología científica, existen actualmente corrientes psicológicas que aplicando un relativismo, no consideran que los trastornos patológicos de índole psicológica tengan un sustento neurológico o sean considerados procesos psiquiátricos, defendiendo una posición de ser una forma de vida o de no aceptar sean considerada enfermedad, que sin embargo, son reconocidos, aceptados y clasificados en la CIE-10, como trastornos de índole neurológico y psiquiátrico. Existen patologías que no son denominadas enfermedades ya sea por su forma de presentación o por su etiología como la enfermedad de Parkinson y el síndrome de Parkinson o el parkinsonismo, igualmente sucede con la fibromialgia; por ejemplo en el clásico ejemplo del síndrome de Down, cuyo origen se encuentra en la trisomía XXI, se evidencian en pacientes que presentan retraso mental y retraso del desarrollo y que aun conociéndose el origen del síndrome, no se han determinado las causas que lo llevaron a ello. Pero el hecho que no sea considerado enfermedad aun no deja de ser un proceso patológico. Analicemos el prefijo neuro, que ya hemos explicado las diferentes formas de su aplicación pero que en realidad no significa neurona, sino nervio, como pasamos a explicar. El médico anatomista, fisiólogo y neurólogo Thomas Willis acuñó la palabra Neurología como el estudio del Sistema nervioso central en su obra Anatomía del cerebro, publicada en 1681. El término neurología fue escrito en griego, "Hemos resuelto emprender la tarea de la Doctrina de los Nervios; y esto más bien porque sin el conocimiento perfecto de los Nervios, la Doctrina del Cerebro y su Apéndice quedarían totalmente cojos e imperfectos" (21). Como dice Arráes-Aybar et al., con respecto a la relación cuerpo-cerebro-alma (21), Wilis afirmó que la filosofía natural y la teología cristiana no deben verse como alternativas o rivales y que la anatomía podría desbloquear los lugares secretos de la mente. Con el término neurología, Willis avanzó con el hecho que no pensaba que los nervios eran tubos huecos por donde corrían los espíritus animales y que el cerebro no lo era todo, sino como sistema nervioso en su división actual, considerando la complejidad de los giros 
La neurociencia y el repensar neurofilosófico en la solución del problema cuerpo-mente.

con la complejidad de la cognición, así mismo los movimientos voluntarios con la corteza cerebral y los involuntarios con el cerebelo. La memoria, la voluntad y la imaginación en la sustancia blanca asociada con el alma humana y el estriado estaba relacionado con la sensación y el movimiento, y que los ventrículos cerebrales contenían el LCR que recogían los productos de deshecho de los efluentes. Es importante el conocimiento anatómico que tuvo en cadáveres, en la preservación en alcohol del cerebro y coloración, así como también las vivisecciones que el conoció.

En el siglo pasado, en base a los descubrimientos del médico y citólogo italiano Bartolomeo Camillo Emilio Golgi y del médico histólogo y anatomopatólogo español Santiago Ramón y Cajal, ambos premios nobeles por sus investigaciones sobre la "Teoría de la neurona" que, propició un momento para que el médico anatomista y patólogo alemán Heinrich Wilhelm Gottfried Waldeyer, se ubique en la historia de la medicina por su contribución sobre sus estudios de la estructura y de la función sobre el sistema nervioso; y fue él, quien utilizó el prefijo neuros como neurona para describir a la unidad estructural básica del sistema nervioso y aunque neuros significa nervio, se utiliza para referirse al sistema nervioso en general y no necesariamente a la mente y menos exclusivamente a ella, ya que la mente, la conciencia, la conducta y el movimiento, son funciones del sistema nervioso. De tal manera que al componerse el término Neurociencia, se aplica a la ciencia que se dedica al estudio, observación y análisis del sistema nervioso del ser humano. Luego, si solo fuera exclusivo de la conducta o del estado emocional del individuo tendría que haberse utilizado la palabra mente, que deriva del latín mens o psyche o psique, que significa alma o la actividad mental como ahora se conoce; de tal manera que se hubiera denominado Psico-ciencia.

Hemos observado que se utiliza indistintamente los términos neurociencia y neurociencias. En cuanto al uso del primer término o neurociencia, se utiliza en referencia a la "Ciencia que se ocupa del sistema nervioso o de cada uno de sus diversos aspectos y funciones especializadas" (18) como lo dice el diccionario de Oxford con respecto a neurología: "el estudio del sistema nervioso" (22). También se utiliza de acuerdo con cada necesidad profesional o de querer estar inmerso en la neurociencia: "El término de neurociencia es aquel que se aplica a la ciencia que se dedica al estudio, observación y análisis del sistema nervioso central del ser humano; también se puede hablar de neurociencia para animales" (23), y neurociencias son las diferentes disciplinas o ciencias neurológicas que tratan sus patologías.

Actualmente, como desde los inicios de la humanidad, se sufren de muchas enfermedades que se van detectando en forma más rápida, gracias a la demostración práctica de la tecnología; pero sigue prevaleciendo el método de la clínica que en medicina nos ayuda a dar una impresión diagnóstica y una prognosis. Entonces, si una persona sufre de ceguera o esquizofrenia, si se queda postrado por parálisis debido a traumas o procesos expansivos tanto a nivel intra craneano como intra raquídeo o de sufrir parálisis cerebral o lo que sucede con los pacientes que sufren de hidrocefalia congénita o adquirida debido a procesos tuberculosos cerebrales o por cisticercosis; como sucede en nuestro país, podemos contestar con tranquilidad que la neurociencia fue una ciencia creada por médicos neurólogos y neurocirujanos que trataron de demostrar la relación del cuerpo con la mente y que hoy sabemos que la mente es un producto emergente y fisiológico del encéfalo que puede ser estudiado en forma transdisciplinaria por médicos y psicólogos actuales, pero también por sociólogos, antropólogos, etcétera. Si alguien quisiera estudiar única y exclusivamente la mente con bases biológicas, puede recurrir a la psicología actual que analiza tres dimensiones: cognitiva, afectiva y conductual, correlacionándola con la biología molecular y genética. Por lo que es recomendable evitar que el discurso sobre la neurociencia solo trate sobre lo cognitivo, lo conativo y la personalidad, pues no solo trata sobre el problema de la res cogita, sino también de los problema de la res extensa. Hay que tener en cuenta que la psicobiología necesita y utiliza la neurociencia, así como la propia psicología requiere de la biología, y al hacerse psicobiológica y científica necesita de la matemática, la química, la física, etcétera. Por lo tanto, es necesario pensar que se incluyen diferentes ciencias para explicar la conducta, el comportamiento, el conocimiento, la personalidad, etcétera, orientado a una concepción biológica y social, pero sin apartarse de su búsqueda primigenia sobre la mente.

¿Cómo deberán ser llamados los estudiosos de las neurociencias? El uso del prefijo neuros, se ha hecho prácticamente masivo, como lo hemos explicado antes y existe el término neurocientífico. Fue el Psicólogo canadiense Donald Olding Hebb, quien inició la Psicobiología, desarrollando una teoría sobre los fenómenos psíquicos relacionados 
a la actividad cerebral. Lo que lo condujo a la aplicación de conocimientos neurocientíficos al estudio del comportamiento. De acuerdo a Redolar (24), actualmente, se considera que la neurociencia cognitiva es la convergencia de la psicología cognitiva que estudia las funciones corticales superiores y la neurociencia que estudia el sistema nervioso. Por lo tanto, sugerimos a quienes dirigen interesantes cursos con el prefijo neuros, en realidad, deberían utilizar el prefijo psyche. Entonces un estudioso exclusivo de la mente podría ser llamado "psychocientífico" (psicocientífico) calificado, de acuerdo con parámetros internacionales.

En relación a un neurocientífico, no basta hacer un curso o una maestría o doctorado en neurociencias para ser considerado un neurocientífico, pues tienen que pasar muchos años de entrenamiento, para comprender la propia senda que se va intentando atravesar en el campo neurológico sea este clínico o quirúrgico, especialmente haber sido formado en el pensamiento médico que involucra el método de la clínica y que con una larga prctica en el ejercicio de la profesión nos permite sustentar las investigaciones; que a través de la historia de la medicina llevó a consolidar a la neurociencia. Para ser considerados neurocientíficos deberán reunir algunos criterios académicos que mencionaremos a continuación, además de ejercer su profesión y no creer que por solo dedicarse a la docencia o la investigación está ejerciendo su profesión, pues tienen que demostrar que trabajan o haber trabajado en centros médicos, hospitales, institutos, etcétera, bajo la tutoría de maestros responsables, que los hayan hecho meditar durante el ejercicio de su profesión sobre sus errores y aciertos, reconociendo que el conocimiento se fundamenta en el esfuerzo y no solo leyendo unos libros de texto o de Internet; debiéndose hacer merecedores de la solución de los problemas en la práctica profesional diaria, concibiendo que él que nunca fue discípulo nunca podrá ser maestro.

De acuerdo con Bear, Connors y Paradiso (25) : "un neurocientífico en los Estados Unidos, ha requerido muchos años de formación, un título o licenciatura profesional, un doctorado en filosofía o un doctorado en medicina o ambas" ... haber "realizado investigación post doctoral bajo la dirección de un neurocientífico reconocido y ser un médico establecido en una universidad, instituto o un hospital". En esta línea de consenso sobre la investigación neurocientífica, ha sido dividida en clínica y experimental. Las profesiones que se hallan inmersas en la investigación clínica, aprendidas desde el inicio de la carrera profesional médica, son todas sus especialidades. Luego, con respecto a la neurociencia, son las iniciadoras de ella, la neurología, la neurocirugía, la psiquiatría que se fue acrecentando gracias a la psicología médica y la neuropatología, que se han ido ampliando con la neuro-imagenología, el neuro-intensivismo, neuro-oftalmología, neurootorrino, neuro-trauma, la medicina física $\mathrm{y}$ rehabilitación, etcétera, dando amplias posibilidades para complementar el diagnóstico y tratamiento de los enfermos.

Con respecto a las profesiones que siguen la línea de la investigación neurocientífica experimental, se encontrarían en relación con las diferentes profesiones relacionadas a la salud: biólogos, etólogos, informáticos, psicólogos, antropólogos, farmacólogos, químicos, físicos, etcétera. Algunas de ellas tratan directamente con los enfermos, ampliando y optimizando las destrezas en el ejercicio profesional, debiéndose actuar de acuerdo con sus competencias en la experimentación práctica y no teórica para realizar docencia e investigación con sustento fáctico.

\section{CONCLUSIONES}

Desde los antiguos filósofos y médicos griegos, hasta la actualidad, se ha buscado dar respuesta al problema de la relación del cuerpo y la mente, llegando a una nueva filosofía en el pensamiento cartesiano durante el medioevo, coincidiendo con la separación de la antigua filosofía y la ciencia. Sin embargo, la eterna lucha entre el dualismo y el monismo material y espiritual continúa, aun sabiendo que la psyche, dejó de ser alma para ser aceptada como mente o razón y ser aceptada como producto fisiológico del encéfalo, pero, no por ello se ha solucionado en forma definitiva.

$1^{\circ}$ El problema de la relación del cuerpo y la mente se encuentra vigente desde hace XXVI siglos.

$2^{\circ}$ La mente es un producto emergente y fisiológico del encéfalo, lo que llevaría a pensar en un monismo materialista, sin embargo el manejo de los problemas se encuentra en un dualismo de la relación del cuerpo y la mente.

$3^{\circ} \mathrm{La}$ neurociencia es una creación histórica de médicos de las áreas de neurología clínica y quirúrgica en sus diversas disciplinas, así como los denominados psicólogos, siendo su representante el médico, fisiólogo y filósofo alemán Wilhem Maximilian Wund que inició la 
La neurociencia y el repensar neurofilosófico en la solución del problema cuerpo-mente.

Psicología Científica.

$5^{\circ}$ La neurociencia y el repensar neurofilosófico la ha desacotado, ayudando a esclarecer los problemas de la relación del cuerpo y la mente.

$6^{\circ}$ Alguna corriente que defiende los aspectos cognitivo, conativo y de la conducta han considerado que es el fundamento de la investigación de la neurociencia, cuando su origen fue con la finalidad de investigar los procesos biológicos de los problemas del sistema nervioso.

$7^{\circ}$ Algunos casos de pacientes han sido conceptuados como formas de vida y dentro de lo normal, siendo trastornos de índole neurológico y psiquiátricos, clasificados en el CIE-10, lo que ha demorado el manejo clínico y terapéutico farmacológico.

$8^{\circ}$ El uso de los prefijos Neuro y Psyche, significan respectivamente nervio y alma o psicología relacionado a la antigua filosofía. Fue con Waldeyer que utilizó el prefijo neuros como neurona.

$9^{\circ}$ Los perfiles académicos profesionales son diferentes, lo que nos obliga a repensar sobre nuestras autolimitaciones en nuestro ejercicio profesional de acuerdo con nuestras competencias con la finalidad de evitar el intrusismo y la intromisión.

$10^{\circ}$ Un neurocientífico es aquel profesional que reúne los criterios internacionales como haber requerido muchos años de formación, un título o licenciatura profesional, un doctorado en filosofía o un doctorado en medicina o ambas. Haber "realizado investigación post doctoral bajo la dirección de un neurocientífico reconocido y ser un médico establecido en una universidad, instituto o un hospital".

$11^{\circ} \mathrm{La}$ investigación neurocientífica, ha sido dividida en clínica y experimental. Las profesiones que se hallan inmersas en la investigación clínica, aprendidas desde el inicio de la carrera profesional médica, son todas sus especialidades.

$12^{\circ}$ Con respecto a las profesiones que siguen la línea de la investigación neurocientífica experimental, se encontrarían en relación con las diferentes profesiones relacionadas a la salud y a la dedicación del estudio y manejo del sistema nervioso.

\section{REFERENCIAS BIBLIOGRÁFICAS}

1. Puma M. Las llaves de la neurociencia y de la neurofilosofía: El ser humano y la persona en la relación del cuerpo y la mente. Lima: PERGRAF SAC; 2019.

2. Ravello BR. Filosofía de la ciencia. Lima: Editores
A; 1993.

3. Roig VL. Experiencia, especie y luz segada: Roger Bacon. Carthaginesia. 2016; 32:305-363.

4. Nelson V, editor. Cronos Diccionario Filosofico. Lima: EBISA ediciones; 2008.

5. Reale G, Antiseri D. Historia del Pensamiento Filosofico y Científico. Barcelona: HERDER; 1988.

6. Laercio D. Vidas opiniones y sentencias de los más ilustres filósofos. 2008th ed. Madrid.: Maxtor; 1914. p.89.

7. Entralgo PL. Historia Universal de la medicina Barcelona: Salvat Editores SA; 1972.

8. Abaggnano N. Diccionario de Filosofía. Ciudad de México: Fondo de Cultura Económica; 1998.

9. Pons-Musso G. Fisicoquímica. Lima: Universidad Nacional Mayor de San Marcos; 1978.

10. Platón. Fedon o del alma. Madrid: Editores M y N, editor; 1871.

11. Pabon-de-Urbina J. Diccionario Griego Clásico Español. 21st ed. Barcelona; 2008. p. 652.

12. Watchtower Bible and Tract Society of New York; International Bible Students Association.. Mankind's Search for God. Brooklyn, New York: Watchtower Bible and Tract Society of New York; International Bible Students Association; 1990.

13. Alonso JR. Historia del cerebro: Una historia de la humanidad. Córdoba: Guadalmazán; 2018.

14. García-Gual C. Tratados Hipocráticos Madrid: GREDOS; 1983.

15. Fernandez-López J. Quirofano y cirugía. Innsbruck, Austria: Hispanoteca. (Citado el 27 de agosto del 2020) Disponible en: http://www.hispanoteca. eu/Foro/ARCHIVO-Foro/Quir\%C3\%B3fano $\% 20$ $\mathrm{y} \% 20$ cirug $\% \mathrm{C} 3 \% \mathrm{ADa}$.htm

16. Merlo JC. Diccionario de ciencias médicas: Dorland. 2nd ed. Buenos Aires: El Ateneo; 1972.

17. Braier L. Diccionario Enciclopédico de Medicina. Buenos Aires.: Heracles; 1955.p.52.

18. Real Academia Española. Parénquima. Madrid: Real Academia Española; 2000.

19. Singh S. Big Bang: The origin of the universe. New York: HarperCollins Publishers; 2005.

20. Ferrater J. Diccionario de Filosofía. 6th ed. Madrid: Alianza Editorial; 1979.

21. Arráez-Aybar LA, Navia-Álvarez, FuentesRedondo T, Bueno-López J. Thomas Willis, pionero en la investigación traslacional en anatomía (en el 350 aniversario de cerebri natome). Journal of Anatomy. 2015; 226(3): 289-300.

22. Oxford University Press Inc. Dictionary of Current English. 8th ed. New York: Oxford University Press Inc; 1993.

23. Navarro J. Definición de Neurociencia. Definición ABC; 2017. (Citado el 27 de agosto del 2020). Disponible en: https://www.definicionabc.com/ 


\section{Puma-Romero M.}

ciencia/neurociencia.php

24. Redolar D. Neurociencia cognitive. Buenos Aires: Editorial Médica Panamericana; 2014.

25. Bear MF, Connors B, Paradiso M. Neurociencia:
Explorando el Cerebro. Barcelona: Masson Wlilliams \& Wilkins; 1998.

Recibido: 08/09/2020

Aceptado: 12/09/2021 